\title{
Re-evaluation of Conventional Cervical Smears with Particular Reference to Revised Bethesda System Criteria: A 5 Years Blind Retrospective and Prospective Study
}

\author{
Sumit Prakash Rathore ${ }^{1 *}$, Manish Kumar $^{1}$ and Rana K. Sherwani ${ }^{2}$ \\ ${ }^{1}$ Department of Pathology, Jhalawar Medical College, Jhalawar, India \\ ${ }^{2}$ Department of Pathology, J.N. Medical College, A.M.U., Aligarh, UP, India
}

\begin{abstract}
Background: The revised Bethesda System of reporting Pap smears in addition to defining the diagnostic categories also develops criteria for determining the adequacy and quality of Pap smears.

Methods: The present retrospective and prospective study was conducted in department of pathology after approval from institutional ethics committee which included retrospective cases from 2007 to 2009 and prospective cases from 2010 to 2011 . Prospective cervical smears were stained by using Papanicolaou stain. After staining, slides were mounted, screened and reported by two consultant pathologists by both Conventional system and the 2001 Bethesda system. Smears which were already reported by the Conventional system were also reviewed retrospectively by the 2001 Bethesda system. Cytohistopathologic correlation was done wherever available.

Result: Results on adequacy of the specimens showed $98.0 \%$ smears as satisfactory and $2.0 \%$ were found to be unsatisfactory for evaluation. Pap smear reporting by both the systems showed similar number of cases with inflammatory findings. $18.3 \%$ premalignant lesions were reported by the Conventional system but it was significantly higher $(31.8 \%)$ when reviewed by the Bethesda system. Numbers of malignant lesions were found similar by both systems i.e. $3.6 \%$.
\end{abstract}

Conclusion: Reporting should be done by the Bethesda System as it improves producibility and helps in diagnose of various intraepithelial lesions and invasive lesions at an early stage and helps to manage them properly.

\section{Keywords: Pap Smear, Bethesda System, Premalignant Lesions, Malignant Lesions}

\section{Introduction}

The highest incidence of cervical cancer occurs in Latin America, the Caribbean, Africa (Tropical Sub-Sahara), and South - East Asia. Around $80 \%$ of the cases occur in developing countries and just $20 \%$ in developed countries. [1] India, which accounts for one sixth of the world's population, also bears one fifth of the world's burden of cervical cancer. ${ }^{[2]}$ There are approximately 132,082 new cases of cervical cancer in India per year and the disease is reported to be responsible for almost 20 percent of all female deaths. ${ }^{[3]}$ India's cervical cancer age-standardized incidence rate $(30.7$ per 100,000$)$ and age-standardized mortality rate $(17.4$ per 100,000$)$ are the highest in South Central Asia. ${ }^{[3]}$

Socioeconomic and cultural aspects are the factors in unequal distribution of cervical neoplasia around the world. However, a preponderant factor in the areas of low incidence is the level of information from the feminine population regarding the disease and the continual screening of this population. On the other hand, in developing countries, the low level of awareness of the problem, and the use of opportunist screening favors the continuance of this unfavourable situation and indicates the urgent need for the public health authorities to find a solution. ${ }^{[4]}$ Cervical cytology was introduced by George N Papanicolaou into clinical practice in $1940 .{ }^{[5]}$ In 1945 , the Papanicolaou smear received the endorsement of the American Cancer Society as an effective method for cancer screening and prevention of cancer. Papanicolaou introduced a numeric classification 1-5 to communicate the degree of confidence that cancer cells were present in the specimen. However, this classification was unable to reliably communicate clinically relevant information. It did not reflect the current understanding of cervical neoplasia with no place for noncancerous entities.

In 1988, the National Cancer Institute (NKI), National Institute of Health, Bethesda, Maryland, sponsored an open workshop including - cyopathologists, cytotechnologists, histopathologists, family practitioners, gynaecologists, public health physicians and epidemiologists to develop a uniform descriptive terminology for cervicovaginal cytology. ${ }^{[6]}$ The recommendations of the 1988 workshop 
received widespread acceptance in practice. The Bethesda System has also replaced the three levels of dysplasia and carcinoma in situ with two levels, Low grade squamous intra epithelial lesion (LSIL) and High grade squamous intra epithelial lesion (HSIL).

A second workshop was held in 1991 to modify the Bethesda system based on the actual laboratory and clinical experience after its implementation. The latest revision of this system was completed in April 30-May 2, 2001 and published in April 2002. Therefore, the present study was undertaken for the better understanding of the method of reporting of the Pap smears and to facilitate the effective and precise communication between pathologists and clinicians at our centre.

\section{Material and Methods}

The present study was conducted in the department of Pathology in a tertiary care teaching hospital. The study design was both retrospective and prospective including retrospective cases from 2007 to 2009 and prospective cases from 2010 to 2011. After approval from institutional ethics committee the study was conducted on the patients attending the indoor wards and the OPDs of the Departments of the Obstetrics and Gynecology. Cervical smears were collected by the residents of the OBG Department using Ayer's spatula along with an endocervical cytobrush after taking informed consent from the patients. These were labeled, fixed in $95 \%$ ethanol and were sent to the Department of Pathology. These smears were then stained by using Papanicolaou stain. After staining, slides were mounted with DPX (distrene dibutyl phthalate xylene), screened and reported by two different consultant pathologists by using both the Conventional system and the 2001 Bethesda system. Retrospectively also, smears which were already reported by the Conventional system were reviewed by using the 2001 Bethesda system. A total of 1000 cases were studied and from each year 200 cases were taken randomly. Cytohistopathologic correlation was done wherever available. All the data were recorded in percentage and the sensitivity and specificity of Bethesda system was used to detect premalignant and malignant lesions.

\section{Results}

A total of one thousands cases were compared by conventional system and Bethesda system. As per the Bethesda system 2001, all the cervical smears were rescreened and commented on their adequacy. Results on adequacy of the specimens showed 980 smears $(98.0 \%)$ as satisfactory for evaluation. Presence of T-zone component was seen in 449 smears $(44.9 \%)$ and absence in $551(55.1 \%)$ smears. All of the specimens were processed properly and none was rejected due to the reasons like broken slide or incompletely filled form etc. Twenty smears $(2.0 \%)$ were found to be unsatisfactory for evaluation. (Table 1)

Inflammation was the most common finding seen in 896 smears $(89.6 \%)$. Out of these inflammatory smears, 865 smears $(86.5 \%)$ showed nonspecific inflammation, while 31 smears $(3.1 \%)$ had organism specified inflammation of which Candida was found in $1.2 \%$ of cases, Bacterial vaginosis in $1.0 \%$, Trichomonas vaginalis in $0.5 \%$ of cases and Herpes and Leptothrix in $0.2 \%$ cases respectively. HPV related changes were seen in $1.7 \%$ cases. Reactive cellular changes due to inflammation were seen in 231 cases $(23.1 \%)$, while reactive changes due to radiation therapy and repair were noted in 13 cases (1.3\%). Atypical squamous cells of undetermined significance (ASC-US) was reported in $2.3 \%$ of the smears, whereas atypical squamous cells- Can't exclude HSIL (ASC-H) was seen in 4 smears $(0.4 \%)$. Low grade squamous intraepithelial lesion (LSIL) was reported in 187 smears (18.7\%). Out of these 187 smears, HPV related changes were seen in 17 cases $(1.7 \%)$. HSIL (high grade squamous intraepithelial lesion) was reported in 60 smears $(6.0 \%)$. Squamous cell carcinoma was noted in 26 cases (2.6\%). AGUS (atypical glandular cells of undetermined significance) was reported in 35 smears $(3.5 \%)$ whereas AGC (atypical glandular cells-favouring neoplastia) was noted in 9 smears $(0.9 \%)$. One smear $(0.1 \%)$ was reported as adenocarcinoma-insitu (AIS), while adenocarcinoma was noted in 4 smears (4\%), adenosquamous carcinoma in 1 smear (1\%) and undifferentiated carcinoma was reported in 4 smears $(4 \%)$. In one smear $(0.1 \%)$ of a reproductive age female, endometrial cells were noted. (Table 2)

For 'specimen adequacy' out of total 386 cases, presence of endocervical cells was noted in 269 smears (69.7\%), presence of squamous metaplastic cells in 98 smears $(25.4 \%)$, and $19(1.9 \%)$ smears was found unsatisfactory for evaluation. The term satisfactory is also not used in the conventional reporting, unsatisfactory smears are mentioned in the reports. In our study 19 (1.9\%) smears were unsatisfactory by conventional reporting and 20 (2.0\%) on reviewing by the Bethesda system. Satisfactory smears were $980(98.0 \%)$ by the Bethesda system which was similar to that by the Conventional reporting i.e. 981 (98.1\%). (Table 3)

Pap smear reporting by both the systems showed similar number of cases with inflammatory findings. Nonspecific inflammation was reported in $85.2 \%$ and $86.5 \%$ by the Conventional system and the Bethesda system respectively. Trichomonas, Herpes, and Leptothrix were found in $0.5 \%$, $0.2 \%$, and $0.2 \%$ cases respectively by both systems, while Candida was seen in $0.8 \%$ cases by the conventional 
system and in $1.2 \%$ of cases by the Bethesda system. Bacterial vaginosis was noted in $0.9 \%$ smears by the Conventional and in $1.0 \%$ cases by the Bethesda system. But the significant difference was noted in the number of premalignant lesions when studied by the two different systems i.e. $18.3 \%$ premalignant lesions were reported by the Conventional system but it was significantly higher i.e
$31.8 \%$ when reviewed by the Bethesda system. Numbers of malignant lesions were found similar by both systems i.e. 3.6\% (Table 4) In our study, the Bethesda system was found to be $100 \%$ sensitive and $100 \%$ specific in detecting malignant lesions while it was $36.5 \%$ more sensitive and $45.5 \%$ more specific in detecting premalignant lesions as compared to conventional system of reporting.

Table 1: Specimen adequacy criteria based on the revised Bethesda system, 2001.

\section{Cytological findings}

Satisfactory for evaluation

T-zone component

\begin{tabular}{l} 
Specimen rejected/not processed \\
\hline $\begin{array}{l}\text { Specimens processed and examined but } \\
\text { unsatisfactory for evaluation } \\
\text { due to }\end{array}$
\end{tabular}

Number of cases (\%) $\mathrm{N}=1000$

\begin{tabular}{|c|c|}
\hline & $980(98 \%)$ \\
\hline Present & $449(44.9 \%)$ \\
\hline \multirow[t]{2}{*}{ Absent } & $551(55.1 \%)$ \\
\hline & - \\
\hline Scant cellularity & $05(0.5 \%)$ \\
\hline Air drying artifact & $04(0.4 \%)$ \\
\hline Completely obscured by inflammation & $08(0.8 \%)$ \\
\hline Completely obscured by blood & $03(0.3 \%)$ \\
\hline
\end{tabular}

Table-2: Findings according to the revised Bethesda system, 2001

\begin{tabular}{|c|c|c|}
\hline \multicolumn{2}{|l|}{ Cytological findings } & $\begin{array}{l}\text { Number of cases } \\
(\%) N=1000\end{array}$ \\
\hline \multicolumn{2}{|l|}{ Smears within normal limits } & $52(5.2 \%)$ \\
\hline \multicolumn{2}{|l|}{ Inflammatory (nonspecific) } & $865(86.5 \%)$ \\
\hline \multirow{5}{*}{$\begin{array}{l}\text { Inflammatory } \\
\text { (Organism specified) }\end{array}$} & Trichomonas & $05(0.5 \%)$ \\
\hline & Bacterial vaginosis & $10(1.0 \%)$ \\
\hline & Candida & $12(1.2 \%)$ \\
\hline & Herpes & $02(0.2 \%)$ \\
\hline & Leptothrix & $02(0.2 \%)$ \\
\hline \multirow{2}{*}{ Reactive cellular changes } & Due to inflammation & $231(23.1 \%)$ \\
\hline & Due to radiation and repair & $13(1.3 \%)$ \\
\hline \multicolumn{2}{|c|}{ Atypical squamous cells of undetermined significance (ASC-US) } & $23(2.3 \%)$ \\
\hline \multicolumn{2}{|c|}{ Atypical squamous cells- can't exclude HSIL (ASC-H) } & $04(0.4 \%)$ \\
\hline \multirow{2}{*}{$\begin{array}{l}\text { Low grade squamous intraepithelial } \\
\text { lesion (LSIL) }\end{array}$} & Human papilloma virus(HPV) & $17(1.7 \%)$ \\
\hline & Mild dysplasia & $170(17 \%)$ \\
\hline \multicolumn{2}{|c|}{ High grade squamous intraepithelial lesion (HSIL) } & $60(6 \%)$ \\
\hline \multicolumn{2}{|l|}{ Squamous cell carcinoma } & $26(2.6 \%)$ \\
\hline \multicolumn{2}{|c|}{ Atypical glandular cells of undetermined significance (AGUS) } & $35(3.5 \%)$ \\
\hline \multicolumn{2}{|c|}{ Atypical glandular cells (favours neoplastic) } & $09(0.9 \%)$ \\
\hline \multicolumn{2}{|l|}{ Adenocarcinoma-in-situ } & $01(0.1 \%)$ \\
\hline \multicolumn{2}{|l|}{ Adenocarcinoma } & $04(0.4 \%)$ \\
\hline \multicolumn{2}{|l|}{ Adenosquamous carcinoma } & $01(0.1 \%)$ \\
\hline \multicolumn{2}{|l|}{ Undifferentiated carcinoma } & $04(0.4 \%)$ \\
\hline \multicolumn{2}{|l|}{ Endometrial cells } & $01(0.1 \%)$ \\
\hline
\end{tabular}


Table 3: Distribution of satisfactory and unsatisfactory smears according to the Conventional Pap and the Bethesda system, 2001.

\begin{tabular}{|c|c|c|}
\hline \multirow{2}{*}{ Findings } & Conventional system & \begin{tabular}{c} 
Bethesda system \\
\cline { 2 - 3 }
\end{tabular} \\
\hline Satisfactory & Number of smears (\%) N=1000 & Number of smears (\%) $\mathbf{N}=1000$ \\
\hline Unsatisfactory & $981(98.1 \%)$ & $980(98 \%)$ \\
\hline
\end{tabular}

Table 4: Comparative study on Pap smear findings by Conventional Pap smear reporting and Bethesda system (n=1000).

\begin{tabular}{|c|c|c|c|}
\hline \multirow{2}{*}{\multicolumn{2}{|c|}{ Pap smear findings }} & Conventional System & Bethesda system \\
\hline & & No. of smears (\%) & No. of smears (\%) \\
\hline \multicolumn{2}{|c|}{ Nonspecific inflammation } & $852(85.2 \%)$ & $865(86.5 \%)$ \\
\hline \multirow{5}{*}{$\begin{array}{l}\text { Inflammatory } \\
\text { (Organism specified) }\end{array}$} & Trichomonas Vaginalis & $05(0.5 \%)$ & $5(0.5 \%)$ \\
\hline & Candida & $08(0.8 \%)$ & $12(1.2 \%)$ \\
\hline & Bacterial vaginosis & $09(0.9 \%)$ & $10(1.0 \%)$ \\
\hline & Herpes & $02(0.2 \%)$ & $2(0.2 \%)$ \\
\hline & Leptothrix & $02(0.2 \%)$ & $2(0.2 \%)$ \\
\hline \multicolumn{2}{|l|}{ Premalignant lesions } & $183(18.3 \%)$ & $318(31.8 \%)$ \\
\hline \multicolumn{2}{|l|}{ Malignant lesions } & $36(3.6 \%)$ & $36(3.6 \%)$ \\
\hline
\end{tabular}

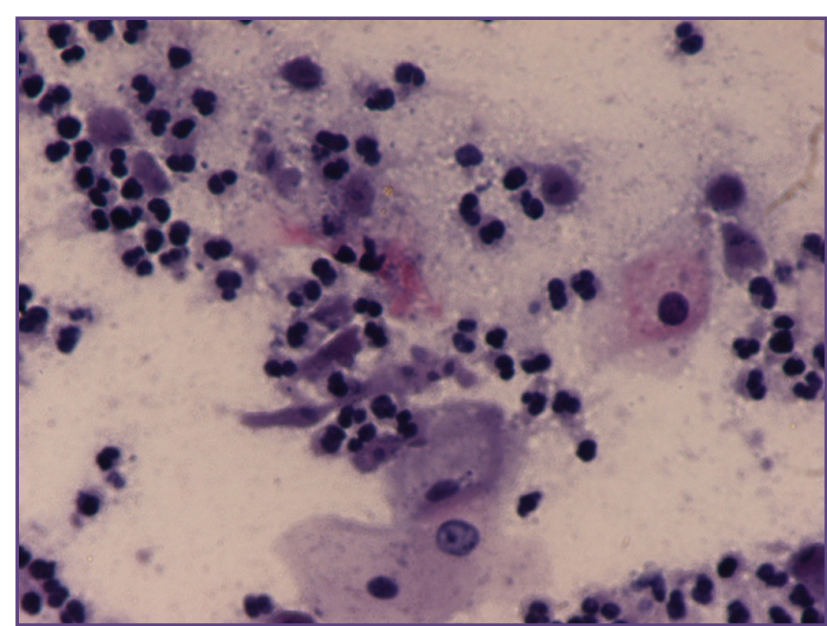

Fig. 1: Smear showing Trichomonas Vaginalis infection 'TV bodies'(pap,40x).

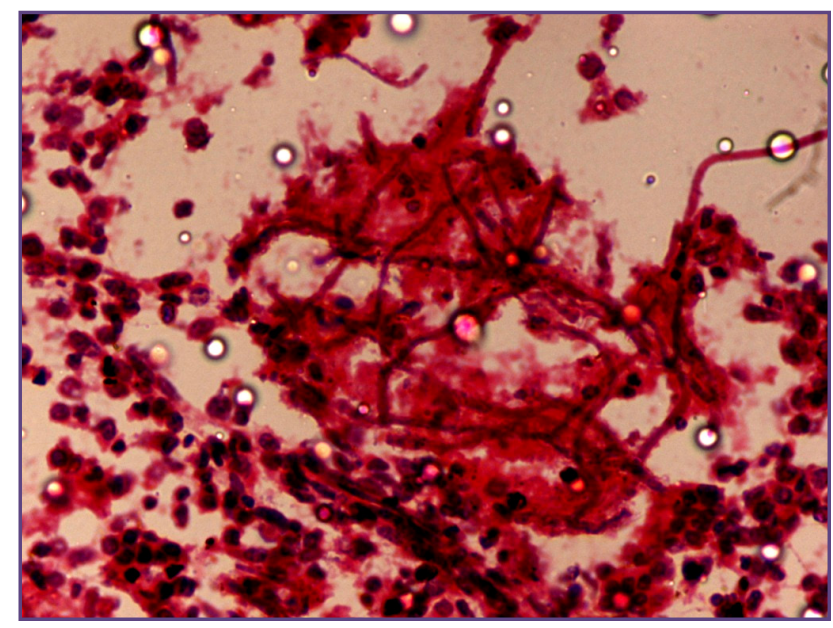

Fig. 3:-smear showing branching hyphae of candida species (pap40X).

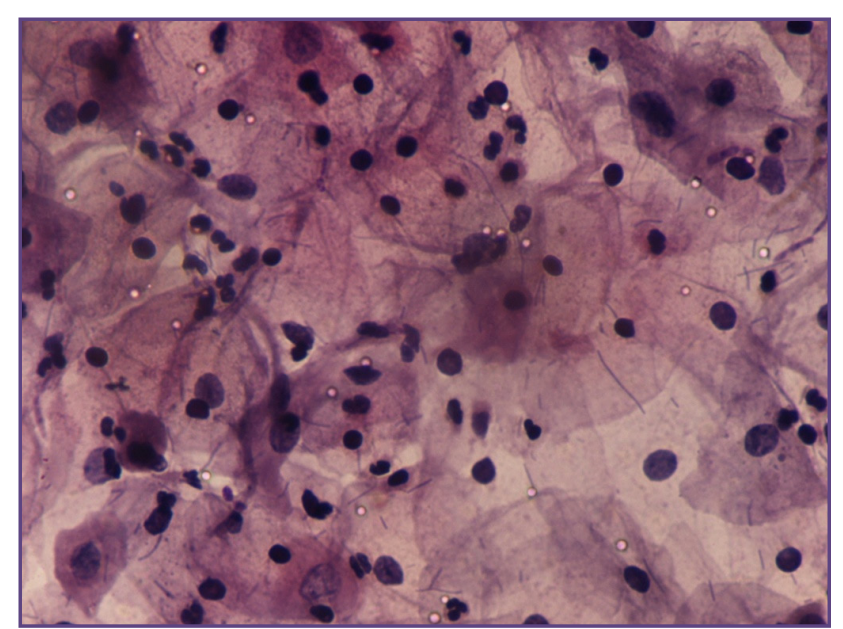

Fig. 2:-smear showing filaments of Leptothrix infection (Pap,40X).

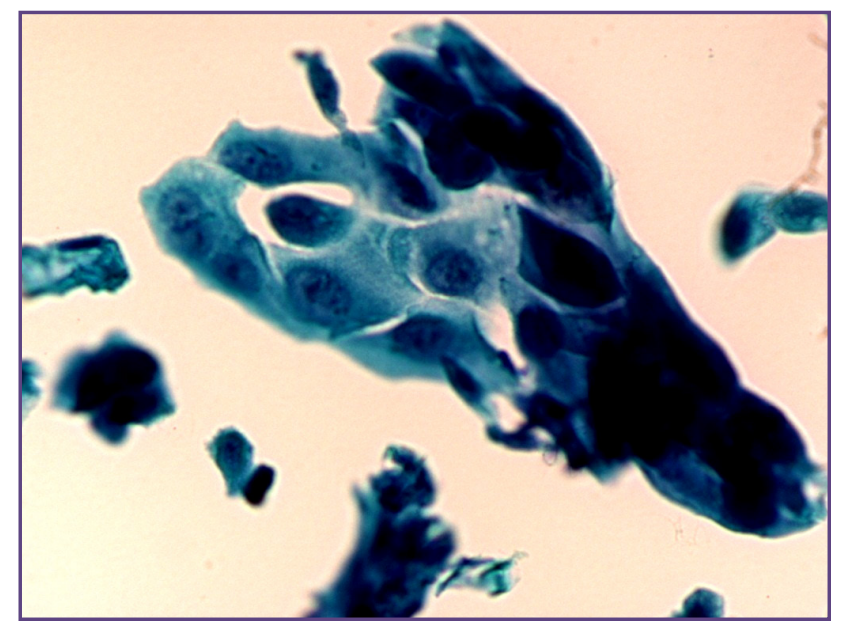

Fig. 4:-smear showing ASCUS-Favour Neoplasia (PAP,40X). 


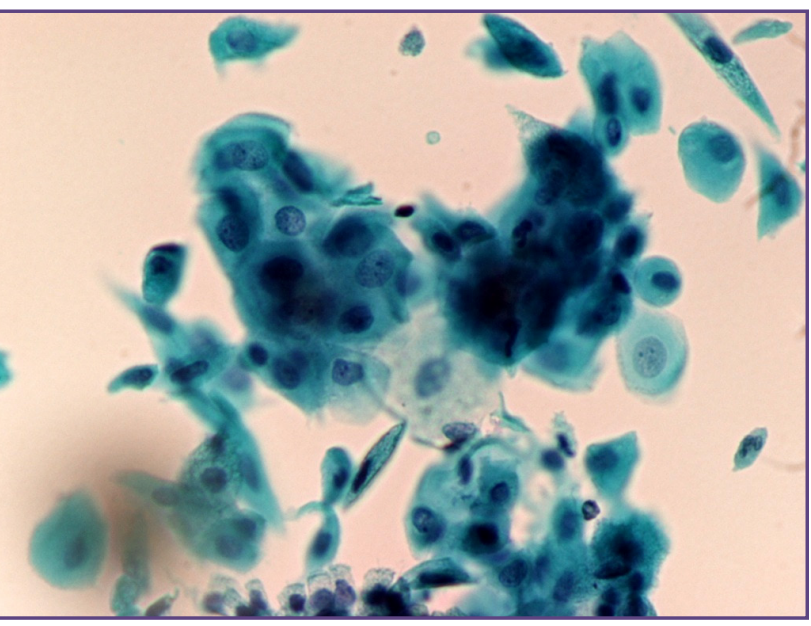

Fig. 5:-smear showing LSIL (PAP,40X)

\section{Discussion}

Reporting of Pap smear is done by the Conventional system and by the Revised Bethesda system 2001. The Bethesda System in addition to defining the diagnostic categories also develops criteria for determining the adequacy and quality of Pap smears. Assessment of the adequacy of a specimen is an integral part of the overall evaluation of a Pap smear. The purpose of designating smears as unsatisfactory is to alert clinicians that the particular smear might not be reliable for detecting preneoplastic or neoplastic conditions. A longitudinal study found that unsatisfactory Pap smears were more often from high-risk patients. ${ }^{[7]}$

All the smears were commented regarding their adequacy on reviewing with the revised Bethesda system. 98.0\% were found satisfactory for evaluation, T-zone component was present in $44.9 \%$ and absent in $55.1 \%$. All of the specimens were processed properly and none was rejected due to any reason. $2.0 \%$ smears were found to be unsatisfactory due to the reasons like scant cellularity, air drying artefact, completely obscured by inflammation or completely obscured by blood.

Like the Conventional reporting, inflammation (89.6\%) was the most common finding with the Bethesda system too. Out of these $89.6 \%$ inflammatory findings, $86.5 \%$ had nonspecific inflammation while $3.1 \%$ had organism specified inflammatory smears. $5.2 \%$ were found to be within normal limits. Atypical squamous cells of undetermined significance (ASC-US) was reported in 2.3\%, whereas Atypical squamous cells- can't exclude HSIL (ASC-H) was reported in $0.4 \%$. Low grade squamous intraepithelial lesion (LSIL) was reported in a

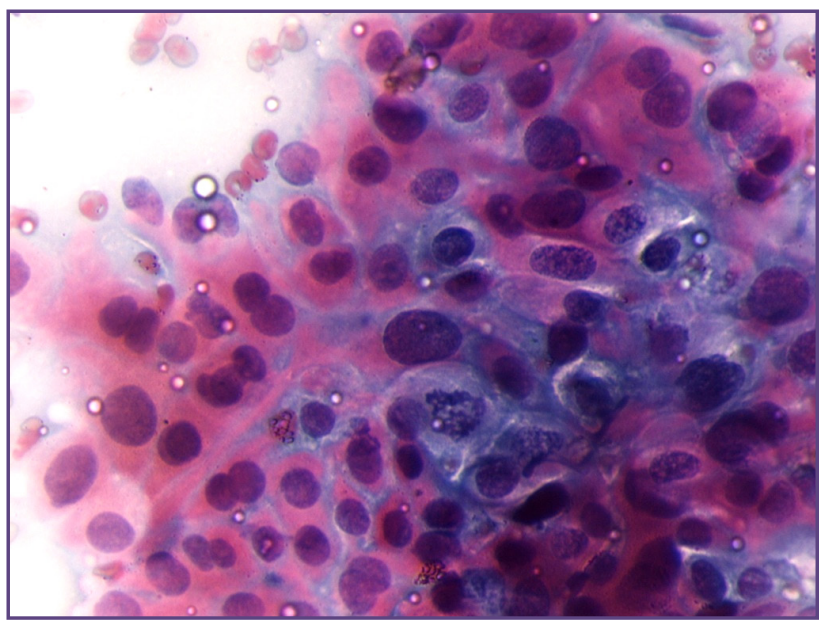

Fig. 6:-smear showing HSIL (PAP,40X)

total of $18.7 \%$. HSIL (high grade squamous intraepithelial lesion) was reported in $6.0 \%$. Squamous cell carcinoma was noted in $2.6 \%$. AGUS (atypical squamous cells of undetermined significance) were reported in 3.5\% whereas AGC-favour neoplastic were noted in $0.9 \%$. One smear $(0.1 \%)$ was reported as Adenocarcinoma-in-situ (AIS). Adenocarcinoma was noted in $0.4 \%$, adenosquamous carcinoma in $0.1 \%$ and undifferentiated carcinoma also was reported in $0.4 \%$.

Our findings are discordant with that of Dhruva et al study, who reported $4.5 \%$ smears as unsatisfactory for evaluation and $37 \%$ smears were in normal limits. $1.3 \%$ smears had atrophic changes, inflammatory (47.5\%), ASCUS (0.8\%), LSIL (5\%), HSIL (2.8\%) and $0.8 \%$ were squamous cell carcinoma in their study. ${ }^{8}$ Our findings are also discordant with the study of Ranabhat SK et al, who reported $26 \%$ with nonspecific inflammation and $2.5 \%$ with reactive cellular changes. Organism specific infections were detected in $9.4 \%$. In their study $3.1 \%$ smears were unsatisfactory for evaluation. ASC-US, AGC and Squamous cell carcinoma were noted in the $0.2 \%$ each, whereas LSIL was noted in $0.3 \%$ and HSIL was seen in $0.7 \%$ smears in their study. ${ }^{[9]}$ Khan MS et al in their study on 546 patients found $9.5 \%$ to be inadequate. $22.7 \%$ were normal, $55.3 \%$ showed inflammatory changes and atrophic changes were seen in the 7.3\%. 1.8\% had LSIL, and 1.3\% had HSIL while Carcinoma in situ, was seen in $2.0 \% .^{[10]}$

Our findings are concordant with the study by Sherwani RK et al, who reported LSIL in $20.0 \%$, HSIL in $4.4 \%$ smears and invasive carcinoma in the $3.75 \%$ respectively. [11] another study done by Abdullah LS, have reported $2.8 \%$ smears as unsatisfactory and $97.2 \%$ as satisfactory 
smears; out of which 5\% were abnormal and these were further classified as ASC-US in $40 \%$, ASC-H in $2 \%$, LSIL in $22 \%$, HSIL in $12 \%$, AGC in $11 \%$ and invasive squamous cell carcinoma in $9 \%$. They also reported $77 \%$ smears as negative for squamous epithelial abnormalities while $18 \%$ as inflammatory/reactive changes. No endocervical or endometrial cells, which favour neoplastic or adenocarcinoma in situ were reported in their study. ${ }^{[12]}$

Although in the Conventional reporting there is no term like 'specimen adequacy' but the following findings may be used to explain it, as we did in our study; presence of endocervical cells was noted in $26.9 \%$, presence of squamous metaplastic cells was seen in $9.8 \%$ and unsatisfactory for evaluation which was noted in $1.9 \%$ smears. These findings could not be compared with other studies as no such study was found in literature. In our study $1.9 \%$ smears were unsatisfactory on conventional reporting and $2 \%$ smears on reviewing them by the Bethesda system. Satisfactory smears were $98.0 \%$ by the Bethesda system which were found to be similar to that by Conventional reporting i.e. $98.1 \%$. These findings are in concordance with the study of Shorey et al, who reported $96.8 \%$ smears as satisfactory and $3.3 \%$ as unsatisfactory. ${ }^{[13]}$ Similar results of around $3.8 \%$ unsatisfactory smears were also reported by Sankaranarayanan $\mathrm{R}$ et al. ${ }^{[14]}$

On comparing the cytological findings of the Conventional system and the Bethesda system, inflammation was found to be the most common finding in both the systems. Nonspecific inflammation was seen in similar number of cases by both the systems of reporting i.e $85.2 \%$ by the Conventional method and $86.5 \%$ by the Bethesda system. Trichomonas, Herpes, and Leptothrix and bacterial vaginosis were reported approximately similar in both the systems. Candida was found slightly higher in Bethesda system. But the significant difference was noted in the number of premalignant lesions by the Conventional system $(18.3 \%)$ and significantly higher by the Bethesda system (31.8\%). Malignant lesions seen by both the systems of reporting were similar i.e. 3.6\%. This could not be compared with any study as none was found mentioning the comparison of two systems.

\section{Conclusion}

It was concluded that reporting should be done by the Bethesda System as it improves producibility and helps in identification of ASCUS and AGUS lesions and plays a key role to diagnose various intraepithelial lesions and invasive lesions at an early stage and helps to manage them properly. Variation in reporting system for cervical smear results can lead to difficulty in communication between pathologists and clinicians, difficulty in comparing results from different centers and in some cases difficulty in selecting the proper treatment for given patients.

\section{References}

1. Parkin DM, Bray F, Ferlay J, Pisani P. Global cancer statistics, 2002. CA Cancer J Clin 2005;55(2):74-108.

2. Sankaranaryanan R, Buduk AM, Rajkumar R: Effective Screening Programmes for Cervical Cancer in low- and middle-income developing countries. Bull World Health Organ 2001;79(10): 954-62.

3. Ferlay J, Bray F, Pisani P, Parkin DM. GLOBOCAN 2002: Cancer Incidence. Mortality and Prevalence Worldwide. IARC Cancer Base No. 5, version 2.0., Lyon: IARC Press 2004.

4. Canfell K, Sitas F, Beral V. Cervical cancer in Australia and the United Kingdom: comparison of screening policy and uptake, and cancer incidence and mortality. Med J Aust 2006;185:482-6.

5. Papanicolaou GN. Introduction of Pap smear in early detection of cervical malignancies. Am J Clin Path 1940;19:301-8.

6. National Cancer Institute Workshop. The 1988 Bethesda System for reporting cervical/vaginal cytological diagnoses. JAMA. 1989;262:931-34.

7. Ransdell JS, Davey DD, Zaleski S. Clinicopathologic correlation of the unsatisfactory Papanicolaou smear. Cancer Cytopathol 1997;81:139-43.

8. Dhruva GA, Agravat AH, Bhojani KR. Analyses of cervical cancer in Rajkot population : Electronic Journal of Pharmacology and Therapy 2011;4:15-20.

9. Ranabhat SK, Shrestha R, Tiwari M. Analysis of abnormal epithelial lesions in cervical Pap smears in Mid-Western Nepal: Journal of Pathology of Nepal 2011;1: 30-3.

10. Khan MS, Raja FY, Ishfaq G, Tahir F, Subhan F, Birjees MK et al. PAP Smear Screening for Pre-cancerous Conditions of the Cervical Cancer. Pak J Med Res 2005; 44:111-3.

11. Sherwani RK, Khan T, Akhtar K, Zeba A, Siddiqui FA, Rahman K et al. Conventional Pap Smear and Liquid Based Cytology for Cervical Cancer Screening - A Comparative Study: Journal of Cytology 2007;24(4):167-72.

12. Abdullah LS. Pattern of abnormal Pap smears in developing countries: A report from a large referral hospital in Saudi Arabia using the revised 2001 Bethesda System. Ann Saudi Med 2007; 27(4 ):268-72. 
13. Shorey G, Shorey P, Kurien A, Joshi VR, Mallick AK. Can the use of ayer's spatula and cytobrush in combination improve the adequacy of cervical smears: International Journal of Applied Biology and Pharmaceutical Technology 2011; 2(2):111-16.
14. Sankaranarayanan R, Thara S, A Sharma, Roy C, Shastri S, Mahe C, et al. Accuracy of conventional cytology: results from a multicentre screening study in India. J Med Screen 2004;11:77-84.

*Corresponding author:

Dr Sumit Prakash Rathore, Assistant professor, Department of Pathology, Jhalawar Medical College , Jhalawar, Rajasthan, India

Phone: +917737295268

Email: drsumitrathore@gmail.com

Date of Submission : 25.07.2016

Date of Acceptance : 27.01.2017

Financial or other Competing Interests: None.

Date of Publication : 03.04.2017 